\title{
A GOOD GIRL IS HARD TO FIND: THE POLITICS OF JANICE GALLOWAY'S THE TRICK IS TO KEEP BREATHING
}

Javier Delgado Delgado

Universidad de La Laguna

$O$ yes

when I was good I was very very good but

but

there was more going on below the surface.

There always is. There is always more to come

(Galloway, 1989: 82).

\section{ABSTRACT}

It is the aim of the present paper to study and analyse the set of deconstructive strategies shown in the contemporary Scottish novel The Trick is to keep breathing by the young author Janice Galloway. Firstly, we focus on the techiniques the main character/narrator, Joy Stone, uses to exxpose and sybvert the inner power relations established between her and the dominant discourses and institutions. The latter are embodied in charaters who occupy positions of power such as doctors, priests, and her bosses at the school and the box-office. The discourses under serutiny vary from popular women's magazines to self-help manuals and maxims. Secondly. we analyse how the main body ofi the text thwarts any appeal to authority through ambiguity, self-contradiction and unreliability. 
Janice Galloway has been one of the most celebrated Scotting authors to emerge in the British literary arena in the 90's. The novel that is held responsible for her unanimous acclaim, The Trick is to Keep Breathing, launched its young author into prominence. It has been termed «an experimental novel» and has been compared with such important contemporary Scotting novels as James Kelman's A Disaffection and Alasdair Gray's 1982, Janice (Gavin Wallace, Ian Spring, Douglas Gifford, 1993; Glenda Norquay, 1997). The emphasis of the critics has been placed on the analysis of a disintegrating, tormented mind-insearch-of-its-identity all those three novels conduct. Equally, some attention has been paid to the study of their fragmented structures, representations of analogous fragmented selves. In the case of the novel that occupies' us here, the fragmented narrative is accompanied by interrupted syntax, unfinished sentences, little asides on the margins, and wide spacing among paragraphs. This design overtly signals the emptiness that surrounds and constitutes the heroine, Joy Stone. However, those aesthetic devices mentioned above are not the concern of this essay. Instead, I have focused on other kinds of narrative strategies, those that impinge directly on the relationships between the main character/narrator and the other charaters and discourses, as well as on the ways the protagonist contradicts and/or undermines her own authority in the novel.

The first question (the narrative strategies) will stress the "deconstructive» quality of the entire novel. That is, we will analyse the different deconstructive techniques the narrator uses throughout the text in her attempts at exposing and contesting the ideology of received, dominant discourses and institutions. In this analysis I have discarded those econstructive strantegies which do not signal power relations but aim at showing the conflict between intention and actual bvehaviour (I am referring here to Joy Stone's attitudes towards charaters who do not exert a direct control over her such as Ellen, the ex lover Paul, or her exx pupil David).

The study or the deconstructive text will be organised following a list of «targets» that are constantly attacked by the intelligent comments of our lady heroine. Such a list would consist of two branches: institutions and discourses. The institutions will come firts, and the include doctor, the schoo, the box-office, and priests. After some consideration has been given to this issue, we will move on to explore the ways the received discourses get «battered". These discourses would include magazines, self-help manuals, and maxims.

The second element of study (the self-undermining authority in/of the text) will be discussed at the end of the paper. We will see why the main text (Joy's stream of consciousness) does and does not deserve to be called «main».

It is interesting to highlight here, before we preceed any further, the reasons why the protagonist of The Trich is to Keep Breathing (from now on TKB) 
needs to lay bare and attack conventions. Joy Stone is a marginal character living in a marginal urban area and working in a school located in an equally deprived zone. Besides, she is going through mental problems and her society has taught her the subject positions she must occupy: patientm employee, defendant, and mistress. The link that binds all these different categories together is powerlessness (one is almost tempted to forgelt that she is also a drama teacher). She is always the second, underprivileged element in the dominant thought system - the rational-, modern paradigm. Under these circumstances, she is forced to use her intelligence and her high self-awareness to reject the language of discourses and institutions that pretends to help her but only works to subdue her. She asserts her position when she questions the power of tarot cards to control life in our postmodern times:

The floor is littered with messages I can't read.

There is no armour against the arbitrariness of things. Not suspicion, not fear. There is no wayi to predict, divine or escape. The only certainty is that there no certainty. Suspicion is never enough (Galloway, 1989: 77).

Suspicion is never enough and, howener, it is the only weapon she possesses to resist imprisoning codes and roles. Suspicion, and a questioning mind, and generous doses of scepticism. As Margery Metzstein accurately observes:

The trouble with Joy is that she always does the wrong thing; that she does not fully understand what is expected of her. Paradoxically, although she is «losing the place» in terms of her prescribed role in society, and does not in a sense exist, she does have enough of a sense of self to be a thorn in the flabby flesh of those authorities witch whom she comes into contact (Metzstein, 1993: 140).

It is this «enough of a sense of self» that prevents her from becoming just a depressed woman who is going through a mental crisis. In the eyes of the reader, Joy turns into a kaleidoscope of contradictory emotions and ideas and it is a pleasure to follow the manoeuvres of her mind throughout the novel.

So far I have been analysing the causes of the rebellious charater of the protagonist. From now I will discuss the "modusi operandi» of her deconstructive techniques and their effect upon the first branch of targets: institutions. I will start with whan I deem to be the most threatening set doctors, health visitors, and hospitals. A battery of strategies is open for Joy to resist and fight back their combined efforts to «improve» and «heal» her. One of the simplest 
methods is the erasure of the doctors' names. All but one, Dr. Stead, are just referred to with numbers -Dr. One, Dr. Two, Dr. Three and so on-. There is a reason for that: the doctors do not «obviouslty» introduce themselves to Joy, the patient, and consequently, she does not know their names. But the effect achieved by the use of numbers is one of detachment and homogeneity, so that the reader is forced to feel antipathy towards them. The one with a name, Dr. Stead, is in no better position. The connotations of his name (steadiness, selfcontrol, power over less strong selves...) overshadow any hint of familiarity and proximity. The scene of Joy's ritual appointment with him further enhances the unbridgeable gap between them through the use of more visual devices.

PATIENT I'm tired and I still need somebody to talk to. I need to get less angry about everything. I'm going nuts.

DOCTORK Don't tell me how to do my job. Relax. You can talk to me. I made a double appointment so we can have twenty minutes. Go ahead. I'm listening.

PATIENT What can I say that makes sense in twenty minutes?

PATIENTK How can I be more like you?

DOCTOR That's not what I meant. That's not what I meant al all. Envy is a destructive emotion. Besides I had to fight hard to get to feel like this. I' $m$ buggered if I'm giving away tje fruits of my hard work for nothing. You must tell me how you are.

PATIENT I don't seem to Know how I am except bad. There nothing there but anger and something scary all the time. I don't want to get bitter because it will ruin my looks.

DOCTOR Maybe a hobby would help. Facetiousness is not an attractive trait in a young woman (Galloway, 1989: 52).

I referred above to the use of categories that overtly point at the roles both subjetcts play in that situation. Our heroine is appointed «PATIENT» and her adversary, "DOCTOR», just a doctor without a name. Both charaters lose their private personalities to become types in a soap opera or comedy of manners. On top of that, the play script layout of the scene underlines the fictitious, performance-like nature of the situation. Once more, the effect is one of detachment, routine, insensibility, and especially, uselessness. The ritualistic nature of the scene prevents us from seeing any real value. We readers observe the uselessness of the entire process and, consequently, the aims and purposes of the medical profession are invalidated. Joy's visual deconstruction proves to be a devastating weapon indeed! Apart from this, the authoritarian character of 
Dr. Stead is asserted dorectly through such forthright sentences as «Don't tell me how to do my job» or «You must tell me how you are» (my italics). Finally there comes one of those rare instances where Joy Stone answers back authority directly, showing her anger and her desperation in the face of the absence of answers for her hunger of knowledge:

IMPATIENT OKK, let's talk straight. You ask me to talk then you look at your watch. What an I supponed to take from that? This whole thing is ridiculous. Can't you send me to someone who's paid to have me waste their time? You don't know what to do with me but you keep telling me to come back. And stop sending that woman to see me. All it does is make me guilty and secretive (Galloway, 1989: 52-3).

It is a rare instance because most of the times such times such bitterness is delivered in inner comments embedded in her stream of consciousness. Nevertheless, this reaction is inscribed in her reluctance to abandon the making of question even though there seems to be no answers. Certainly, the medical profession is not going to provide any.

Further on in the novel, Dr. Stead reappears on stage within the musings of our heroine. This time, criticism of his methods and his therapy (or its absence) is carried out irony and the acknowledgement of Joy's penchant for lies and deception as another means of survival.

Right from the first, Dr. Steak wanted to handle things his was. The Stead method was drugless: he thought if I took anything it would just delay what he called full awareness... Dr. Stead had been hoping for a more straightforward case... But he hung on. Sleeping pills reluctantly, tranquillisers then anti-depressants when the things that were supposed to be passind off didn't. Red ones, yellow ones, green capsules... Poor Dr. Stead. I don't tell him the half of what I do. I'm a liar and a cheat with Dr. Stead while he sees endless queues of sick people and tries to make room for me (Galloway, 1989: 95).

The eviden contradiction in Dr. Stead's prescriptions is too large to bear. The capsules and pills are designed to help her overcome her anguish but they only cause her to loose "full awareness». Dr. Stead is reluctant to prescribe them yet he keeps doing precisely that so as not to solve the problem but to delay it. Maybe he expects Joy, patient, his problem, to fade away, to conform to the way things are. 
Things do not get better once the protagonist/narrator is admitted to Foresthouse Hospital for psychiatric treatment. Within the walls of this institution time passes by for Joy without any notice a recovery. Doctors play the game of hide and seek; the medicines keep coming at their appointed times; the other patients wander in their own worlds as alienated and lonely as Joy Herself. But the problem with Joy is that she cannot avoid thinking too much. From the beginning she consciously submits herself to the game of power shifts that circulate throughout the hospital. The first meeting with Dr. One shows her problems with expressing herself?

A few weeks? I said, not much louder than a whisper. I started crying again. The power had shifted completely to the other side of the desk without my noticing how he did it.

A few weeks, he said. He was very definite...

... I couldn't say what really worried me. What really me was the idea of supervision, mealtimes, other people. And the terrible knowledge it wouldn't make any difference anyway. I said none of that (Galloway, 1989: 108).

Here is Joy pretending to accep her new role as hospital resident while her mind works furiously on the anticipating of bad times to come. Once more, her voice is strangled and erased by the more powerful ones of those who know better. This is one of the similarities that our heroine shares with the main characters of Kelman's A Disaffection and Gray's 1982, Janine, only that a feminist stance is added to the familiar urgency to speak. This aspect of the novel has been pointed out by Gavin Wallace, who also related it to the concern of this paper, the politics of $T K B$, when he asserted that

Joy Stone is seen to suffer... from an inarticulable grief and a voice from which she remains dissociated. Even when it tries to speak, it is a voice repeatedly drowned out by a sinister chorus of louder, external ones - those of insensitive psychiatric opinion, of authoritarian employers, of exploitative women's journalism - which conspire to eradicate her emotional claim on the memory of her dead lover... (Wallace, 1993: 223-4).

In spite of that repressed voice, later on she will find out that the ill and the infirm also possess power, a power that discomforts and disturbs the sane, «normal» people who will come to visit her. At least while you are ill you can be dispensed with the terrible responsibility of finding a suitable identity for yourself. You lack the energies to start such an enterprise. Instead, you can 
abandon yourself to the care of medicines and routine. They will do the hard work for you.

If the help of medicines and the medical profession was not enough the heroine would also enjoy the benefits coming from her profession as a schoolteacher. I mentioned earlier in this essay that it is easy for the reader to forget this point. Most of the times she does not attend school and besides, her position ther is more that of an employee than that of a teacher. With this «subtle» change of perspective we are given new glimpses of Joy's alertness against the evil lying behind words, behind discourses.

One of the clearest instances of deconstruction at work in the novel occurs early, on pages 11 , when Joy reflects upon what it means to be a teacher and to work in a school:

This is my workplace.

This is where I earn my definition, the place that tells me what I am.

Work is not a problem. I work in a school.

I teach children.

I teach them:

1. routine

2. when to keep their mousths shut

3. how to put up with boredom and unfairness

4. how to sublimate anger politely

5. not to go into teaching

That isn't true. And then again, it is. I am never sure what it is I do. (Galloway, 1989: 11-2).

The workings of ideology are exposed here in all clarity without the need to mention the word explicitly. For any ideology to persist and persuade the subjects of its tenets it has to cover itself with pleasurable and desirable garments. So there is an attractive surface that hides values and assumptions that could be less attractive if laid bare. This exposure is what Joy Stone has produced in this instance. The reader is shocked and repelled at the revealing of the ugly truth that hides behind one of the noblest institutions of any society: education. The shocking effect is accompanied by one of detachment and mechanisation. The extremely short sentences, the repetitions of verbs and sentences, and the bareness of their meanings contribute to elicit negative responses on the part of the reader. The final paradox, «That isn't true. And then again, it is», forces the reader to beware appearances, reminds us of Joy's inner duplicity, and sets the mood for more deconstructive strategies to come.

One of these strategies proves to be poweful and, at the same time, shows us Joy's vulnerability in the face of oppressing discourses she paradoxically in- 
corporates and erases in her mind. I am referring to the repetitions of certain pieces of advice that are supposedly designer to help her. But their very repetition invalidates her and our trust in them. Since we are still dealing with Joy's problems with school and school authorities, let us pause to analyse the effect such repetitions produce when her presence is required at Mr. Peach's office, the school headmaster. The school is about to celebrate a Service for Michael Fisher, Joy's lover and work companion, who died because of an accident. The situation is a difficult one since Michael was also married to another woman and his widow is also going to be there, «of course». Mr. Peach does not want to run any risks and expects Joy to be «reasonable».

I said, It's nice of you to ask me. I appreciate being asked. He wiped his nose and nodded so I knew it was the right answer. I was supposed to appreciate being asked. But I was still cautious: personal questions don't belong where people work so I knew I had to look out for hidden agenda. I thought I was being so careful...

... Mrs Fisher will have to be invited. Of course.

The of course was thoughtful and unnecessary. I wanted to be civilised and polite. I had a thing about being civilised and polite... course.

... Yes of course, of course Mrs Fisher should be there of

I appreciated being asked. This was my workplace. It made me warm to be so valued. Of course of course of course... It was all settled (Galloway, 1989: 73-4).

The battery of repeated sentences points in two directions: on the one hand, it singnals the distance between the imposition of external discourses upon Joy's mind and her awareness of their twisted intentions; on the other hand, it also indicates the degree of familiarity and internalisation those discourses have reached. Joy proves to be very accustomed to accepting (or rather pretending to accept) the propriety of the social discourses that aim to male a «normal» person out of her.

The rendering of the Service on pages 78 and 79 puts Joy into contact with another institution: the Church and it ministers. Those pages contain one of the most painful recognitions of Joy's radical opposition to everthing that has ever mattered in Western history. The Church and the social conventions conspire to overtly exclude our protagonist from everything on earth that is thought of as worthy and respectable. But, as usual, there is a deconstructive 
technique coming to her rescue. This time it is an interesting pairing of discourses that elicitss a response against that attempt at erasing her. Written in the form of columns, the reader gets a very visual confrontation of discourses: on the left, the authoritative discourse of the Church delivered bu mouth of Rev Dogsbody in capitl letters (the visual sign of authority and power in much feminist writing, $T K B$ included); on the right, the sparse and unfinished comments of our heroine that predict the worst to come: the implicit acknowledgement of her illicit status as mistress once the minister only has word for the widow and Michael's family. Then she reflects upon the damage that has been done on her:

1. The Rev Dogsbody had chosen this service to perform a miracle.

2. He'd run time backwards, cleansed, absolved and got rid of the ground-in stain.

3. And the stain was me.

I didn't exist. The miracle had wiped me out.

The first symptom of non-existence is weightlessness.

The second is singing in the ears, a quiet acceptance of the unreality of things. Then the third takes over in earnest.

The third is shaking (Galloway, 1989: 79).

Joy's bitterness is all the more painful and aggressive precisely because it is kepti within the confines of her thinking. It is self-destructive but succeeds in questioning the tenets of an institution that preaches the defense of the interests of the excluded and the miserable, and ends up excluding those it pretends to help.

If there is an abyss between Joy and her appointed roles as patient and employee, the distance is not different when is comes to her other work at the boxoffice and, above all, to her other boss, Tony. There is much feminist thinking and feminist deconstruction in this novel, but it is in Joy's «affair» with Tony that we get the most salient and over feminist aspects of the novel. Tony is her boss and plays at becoming? her wayward lover. Unfortunately for him, the first condition exerts more influence upon Joy's consciousness than the second one. Thus, we are constantly reminded that Tony's one aim is to prey on Joy just because she is a vulnerable woman. He pretends that he cares for her but in fact showing her who is the boss all the time.

Once of the clearest instances of this occcurs on pages 92 and 93 . There, under the now familiar play script layout and the equally cold and unattached roles the characters play, the reader is offered a clear dismantling of 
Tony's position and intentions by means of Joy's ever alert consciousness. Tony tries to persuade her to go for a night out him but his victim is not going to give in:

ME I'm kind of busy this afternoon.

PHONE What do you mean busy? Look, just an hour or two, that's all. I'll give you a lift back so you can change for tonight that's worrying you.

ME Well, maybe. I'll think about it OK? But I can't come tonight. [Inspiration] I'm having a meal with Ellen.

PHONE Break it. She'd understand.

ME No, I'm sorry Tony. I can't. I really can't. You wouldn't like me to break a promise.

PHONE Well, worth a try. But she doesn't have all that many runs left this season. [Means There's something wrong with you, going to see an old lady instead of grabbing the change with me I'm used to better things I can any amount of girls you know don't you realise what you're being offered here?] Better catch you early next time eh? [Means I know you're just playing hard to get]

ME Yes. I'm sorry Tony. I am. I'm sorry.

PHONE No skin off my nose. I'll forgive you this time. [Means Don't let it happen again and remember I'm your boss]. Anyhow I have to get back to work. We don't all have the day off. Ciao.

ME I'm sorry (Galloway, 1989: 93-4).

Tony's unbearable sense of superiority, his authoritative attitude and domineering character are underlined in this passage through the subtlety of the unsaid. Once more, words are treacherous weapons that conceal more than they reveal. The typicality of the situation is rendered comic and Tony's patriarchal purposes are mocked in spite of the tension of the whole passage.

Every meeting with Tony is conducted as if Joy werw walking on a minefield. The style is usually marked by a cruel detachment and a desperate sense of passivity on her side. The separateness of the two «lovers» is made kapparent. It is as if they were inhabiting two completely different worlds. When Tony tries to make love to her, they are miles away from each other. She abandons herself to his empty arms when she is too tired to fight back. However, her criticism of his manners is always present and one senses that it could be applied to other, similar masculine attitudes performed by men like Tony. The sheer economic nature of their meetings is highlighted on page 174 when we are informed that: 
He invited himself into the livingroom, sat on the sheet-covered sofa flicking cigar ash into the neck of an empty bottle. I didn't say no. His mouth over mine was warm and made me lonely... I would not sit on his knee the kissing was taken for granted. He had paid good money, after all. A meal, a dancing, flowers...

... I tried to laugh but I was too tired. He said I can't get you out of my mind. I think about you all the time. What does it mean? What does it mean? Something caught in my throat when he spoke. A spark of terrible anger that he should dare say things like this, expecting me to listen. A spark. I swallowed and said nothing. I made excuses. Maybe he thought women liked to hear this kind of thing (Galloway, 1989: 174-5).

Tony's sentences are deprived of meaning out of too much abuse. What can idioms such as «I think about you all the time possibly mean»? Joy's response is her accustomed inaudible agony, an inarticulate spark that is drowned as soon as it glitters. She is not sure of what he thinks. She is never sure of anything because she is suspicious of everything. She can only guess by the way he behaves. Thus, the distance between the sensible woman an the typical man is all the more unbridgeable.

Hospitals, the school, the box-office, the Church, all these istitutions and their dominant and domineering discourses we have been discussing so far belong to a rigidly hierarchical society ortanised in terms of equially immobile binary oppositions. We have already mentioned the secondary position the heroine of $T K B$ occupies in those oppositions. Before we move on to deal with the dismantling of the second brand of targets, discourses, let us conclude the discussion of Joy's relation wint actrual institutions with the one example that summarises her attitude towards the society she has to live with. I am referring to pages 81,82 and 83 , where Joy Stone exposes the values that hide beneath the respectable surface of the Good Girl model. Drawing on feminist and Marxist criticism she explodes the power structures that operate beneath such a "pleasurable» category to show its mercenary qualities? Hers is the deconstructive indictment of a society that is governed by what Michael Foucalut called «the instrumental reason» (Waugh, 1992: 74), a miscarriage of the original Enlightenment project. A reason that enshirines all that smells of productivity and forbids the feelings, the diversions, and the spontaneous elements of human nature. These are not productive; on the contrary, they lead to the moral to the moral degeneration of the body and the soul. The general repression of the sopontaneous that affects? our contemporary capitalist societies is linked in $T K B$ to a specifically Scottish malaise, where «Love/Emotion = embarrassment: Scots equation." (Galloway, 1989: 82). 
The malaise is organised around two key terms: being good the idea of reward. The intended meanings of such a benevolent adjective are shown in their diversity and wickedness. What they all have in common is their capacity to subdue, to dominate the subject is forced to play a passive role, forced to accept its duties and obligations with a hearty spirit. There is always someone else who knows better. At least Joy is able to unmask the purposes of those who have been trying to define her since her childhood:

... I used to be so good all the time.

[where good $=$ productive/hardworking/wouldn't say boo] I was a good student... People made jokes, I was so eager to please. That's how good I used to be.

[where good $=$ value for money] $\mathrm{I}$ was very good at my mother's funeral though largely by default. [where good = not putting anyone out by feeling too much, blank, unobtrusive

Michael's was my first burial... I managed. I was tasteful because I wanted people's approval. Good girls reap rewards.

[where good = neat, acting in a credit-worthy manner]

... I was discreet. I knew the whole thing was a matter of lasting out. If I was a good [ie patient, thoughtful, uncomplaining] girl long

enough I would reap the reward (Galloway, 1989: 81-2).

If the purpose of being good is to conform to the prevailing social conventions, the nature of the reward to be obtained ar the end is imprecise. The reader is not allowed to get a glimpse of what this reward can possibly be precisely because Joy herself is not sure about it. There is also an equal amount of uncertainty about the coming of that «promised» end. Will it not refer to the afterlife? Does it have anything to do with professional or sentimental fulfilment? The only available, depressing answer seems to be that there is only a «lasting out» that would take ages. Mixing literary with popular references in what constitutes a typical postmodern dialogue, our heroine reflects on her tragic condition and the vicious circles others keep on imposing her:

all I wanted to be was civilised and polite. I wanted to be no trouble. I wanted to be brave and discreet. This has to be the final stage of the endurance test and all I had to do was last out. I thought I was Bunyan's Pilgrim and Dorothy in the Wizard of Oz. But the lasting out was terrible. I made appointments with the doctor and he gave me pills to tide me over when I got anxious. I got anxious when they didn't tide me over into anything different. He gave 
me more pills. I kept going to work. I was no nearer kansas or the Celestial City. (Galloway, 1989: 83).

As the reader gets to know at the end of the novel, it is only by forgiving herself and finding her own voice that she can escape those vicious circles. Until then, she will be tied to the pills of indifference and insensibility.

If Joy's contacts with power through her analysis and awareness of their institutions are not enough, she can also prove her rebellious character against the other branch of targets I introduced early on this paper: the textual discourses she has to face thoughout the novel. Let it be remembered that it is discourses that she is fighting against all the time through the greater discourse the novel is. However, as I announced at the beginning of this essay, I decided to separate the overt textual discourses from those embodied by characters in positions of power.

The first of these textual discourses is that of women's magazines. These texts are the most? insidious since they recruit high percentages of loyalty among their usual readers. Their acceptance and popularity among urban women are due to their apparently innocent pieces of advice about how to make the perfect woman. Their powerful marketing strategy consists in the creation of a need: the need to follow the standards, rules, and conventions those magazines have set according to what they think is good for the modem woman. As a consequence, women become victims of unbearable pressures in their pursuit of certain imposed objectives: the best body, the right behaviour, the right clothes to wear at any time, the right words to say to the husband or lover... Through her usual reflections upon the pressures to conform exerted by any kind of power, Joy Stone dismantles women's magazines' aims when she realises that

Magazines told me to work on my awareness I would wake up and thinl this is my One Shot at Today. I'm Young, Dynamic, Today's Woman. I'm Multi-Orgasmic. I have to Live Life to the Full. I didn't know what this meant but I thought it anyway. At the start of every day. It become pressing. I would get anxious if I hadn't done something new, discovered something, found a direction for my life (Galloway, 1989: 193).

The use of capital letters points at the persuasion exerted by magazines' headlines, while, at the same time, this persuasion is rendered useless due to the typicality of these headlines. They are nothing but idioms, exhausted forms of a tired language out of too mucho repetition. However, their meanings are 
never completely clear: What can we make of «Live Life to the Full»? Or why is every modern woman «Today's Woman»? The elusiveness of their messages does not prevent their manipulative strength.

If Women's Magazines can do nothing to help a sensible, self-aware character as Joy, what can be expected of other, similarly persuasive discourses susch as the self-help manuals? There is only one mention of this kind of discourse in the novel, but it is enought to laugh at Joy's cruel indictment. The instance in question is entitled Courage and Bereavement, and we can sense Joy's scepticism towards what she is reading. A scepticism sustained as much by the use of the indirect style and the repetition of the formula «it says» as by the ironies contained in the summaries of the chapters of the manual. One of the most poignant ironies emerges when chapter 3 recommends her to get nearer to her family (Galloway, 1989: 171), and by that page we all know that her family is almost non-existent. Chapter 8 prescribes her to talk to those people in positions of power (doctor and priests) she had been avoiding all the time (Galloway, 1989: 172). The authoritative quality of the discourse is underlined by a succession of "musts" and «should do's», and, finally, the entire experience explodes when she states that «I read the book in two and a half hours and cry all the way through. /Like watching Bambi.» (Galloway, 1989: 172). No comment.

When self-help manuals fail there comes the turn of maxims and slogans. These brief, neat, direct, and convincig sentences pretend to offer ready solutions for long, unresolved problems. They emerge like brilliant sparks in the middle of black despair, and thus, their efficacy seems to be taken for granted. They just have to be recited aloud several times (or as many times as necessary), and the «miracle» is performed. Nevertheless, and as usual, maxims and slogans hide the effort and the strength that are needed to achieve what they propose. And our heroine is ready to reflect upon this, almost at the very moment of trusting their efficacy.

I should refuse to see Dr. Three again. He always makes things worse. My notebook will be better than a doctor. I have to learn to minister to myself and let the slogans teach me something. Maybe that was the idea all along.

I write:

Persistence is the Only Thing That Works.

I forgot to write:

Beware the Maxim.

Neat Phrases hide Hard Work.

Everything Worth Having is Hard as Nails.

I forgot there is always a price for forgetting (Galloway, 1989: 173). 
Here we have a visual presentation of a deconstruction similar to that used by Joy when she criticised the shool system and her routine as a teacher. However, the irony in this instance seems to be overwhelming. The discourse under attack - the maxim - can only be thwarted by using that very discourse it tries to erase. Is this not a typical postmodern paradox if one agrees with what Linda Hutcheon has taught us about postmodernism? That is, is not Joy Stone underminig and, at the same time, inscribing the discourse she wants lto expose and criticise? And, if this is the case, Joy Stone is not doing anything to get free from the vicious entrapment of discourses like slogans. In spite of this contradictory movement, we know that, by the end of the novel, the heroine is able to move beyond the quietness that surrounds her and affirm her own voice. But the persistence of this kind of contradictory steps in the heroine's path should warn us against any easy acceptance of the «sovereignty» of her own authority in the novel. Moreover, it is one of the claims of this paper that her own authority is also undermined by the very discourse that imposes it. We will look at it the end of the essay.

After reading the novel, one senses the diferrence between the fragmented and dislocated structures and layout of TKB and the apparent cohesiveness and unity of the dominant discourses I have been analysing throughout this paper. Nevertheless, this difference is misleading. And the reader should be aware of that once the deconstructive techniques have done their work. As a summary of the misleading nature of all the domineering discourses Joy has had to cope with, I would like to bring here a quotation from Glenda Norquay, which I deem to be precise and complete. She asserted that Joy «... has to accept that the narratives, the discourses in which she is entrapped will not offer order and completion, will always be partial, insubstantial, inadequate - and that which appears cohesive is in fact that most fragmented, fragmenting and coercive." (Norquay 1997: 327). As a consequence, $T K B$ stands as a battlefield between two sets of fragments: those of the dominant institutions against those that belong to the disturbing consciousness of our protagonist.

It is this consciousness that constitutes the main body of the novel. When questions of authority are concerned, it would be interesting to discuss the ambiguity of the qualifier «main». Why is it an ambiguous qualifier? I contend that although Joy's discursive consciousness is constantly interrupted and fragmented by the intervention of other discourses, this fact does not significantly alter the authority of her voice. And this is so because these other discourses are so fragmented, unfinished, and scattered, and their presence is so irregular, that they do not pose a serious threat to the mental speculations of our heroine. All they can do is to compete for the attention of both, character/narrator and reader. If these discourses are powerless to effectively undermine the authority 
of Joy's voice, what is it that performs such a task? Well, I am afraid that it is the very discursive consciousness of the protagonist that plays such a role. It is the self-contradictory and unreliable (or, at least, not completely reliable) nature of her narrative that guarantees the ambiguity of its status as «main body of text». Thus, if this consideration was maintained on the grounds that her narrative overwhelmingly occupies most of the textual space (and so it is the main discourse in the novel), such a status would be questioned by the elements that work to thwart any appeal to authority. This is why I stated at the beginning of this paper that the main narrative of the novel is and is not the «main» one. As a consequence of all this, $T K B$ avoids the trap of becoming as authoritative and univocal a text as those it sets to deconstruct.

So the novel under discussion here prevents us from reaching neat, complete and safe conclusions. But, how is it going to do it? In other words, which are those elements I mentioned above that thwart any appeal to authority? Well, the same elements or strategies she has been using to expose the ideological assumptions of the discourses she attacks. Ot these, irony, self-deception, lies and numerous gaps in meaning are the most powerful. Most of the time it is difficult to separate the irony of her remarks from the degree of internalisation of the discourses she criticises (remember the example of the maxims used to dismantle the power of maxims). The unreliability of her voice shows itself in the typographic nature of the novel - characterised by multiple spacing and toying with textual space on the page. But this unreliability is also manifest in the content of the narrative itself, specifically when she herself acknowledges that she is an incorrigible liar. This acknowledgement comes after one meeting with the Health Visitor. She lies when asked and then, she feels guilty about it all: «... Today, the important thing is not to think about the Healt Visitor and just keep moving. I lied. No-one is visiting toningt. Or tomorrow night. They did once but not now. I told a lie. I tell lies all the time.» (Galloway, 1989: 25). One unwanted consequence of her lies is the guilt she undergoes later. A guilt that functions as an anti-strategy that counters the irony and the other deconstructive techniques I have been discussing all along. A guilt that turns against her and gives her back all her bitterness and disaffection.

Janice Galloway has produced not only an experimental novel, but also a fully postmodern and feminist novel, thought there are no meta-fictional devices to account for its postmodern quality. However, it is the concern with power structures and ideology, that is, with politics. that persuades me to include $T K B$ in the tradition of the contemporary postmodern novel (as opposed to the concern with morals more typical of the realist novel). Through abundant use of deconstructive strategies, the narrator/main character assaults the ugly faces hidden beneath and beyond attractive discursive practices and institutions. But 
this distrust of any authority in the text itself so that the plurality of visions, the competition of registers and discourses without clear winners, and the refusal to impose any univocal, convergent perspective are preserved. After reading the novel, one has to understand that not only is a good girl hard to find, but also that that demand is not even necessary or desirable.

\section{BIBLIOGRAPHY}

Belsey, Catherine, (1980): Critical Practice, London, Routledge.

Galloway, JANICE, (1989): The Trick is to Keep Breathing, London, Minerva. Hutcheon, Linda, (1988): A Poetics of Postmodernism: History, Theory, Fiction, London, Routledge.

Mchale, Brian, (1987): Postmodernist Fiction, London and New York, Routledge.

Metzstein, Margery, (1993): «Of Myths and Men: Aspects of Gender in the Fiction of Janice Galloway», The Scottish Novel Since The Seventies, Eds. Gavin Wallace and Randall Stevenson, Edinburgh, Edinburgh University Press, p. 136-146.

Norquay, Glenda, (1997): «The Fiction of Janice Galloway: "Weaving a Route through Chaos" "Space and Place. The Geographies of Literature, Eds. Glenda Norquay and Gerry Smyth, Liverpool, Liverpool John Moores University Press, p. 323-330.

Wallace, Gavin, (1993): «Voices in Empty Houses: The Novel of Damaged Identity», The Scottish Novel Since The Seventies, Eds. Gavin Wallace and Randall Stevenson, Edinburgh, Edinburgh University Press, p. 217-231.

Waugh, PAtricla, (1992): Practising Postmodernism/Reading Modernism, London and New York, Edward Amold. 